\title{
Determining magnetotail reconnection location from polar rain energy dispersion
}

\author{
Yongliang Zhang and Simon Wing \\ The Johns Hopkins University Applied Physics Laboratory \\ Laurel, Maryland, USA
}

\begin{abstract}
An improved algorithm was developed to estimate the polar rain electron path length from the magnetotail X-line to the polar ionosphere using the information of polar rain electron energy-latitude dispersion. Recent particle tracing simulations using APLOPM model (Applied Physics Laboratory - Open-field line particle Precipitation Model) [Wing et al., 2001; Wing and Zhang, 2015] indicate that an existing or traditional method underestimates the path length by at least $33 \%$. A new method for estimating electron path length that introduces a new parameter (energy parameter) is proposed. The improved algorithm has been validated using the APLOPM simulation data. By applying the new algorithm to two real events measured by DMSP satellites, we found the polar rain electron path lengths of 67 and $114 \mathrm{R}_{\mathrm{E}}$, (X-lines estimated at $\mathrm{X}=-54$ and $-91 \mathrm{R}_{\mathrm{E}}$ ), respectively (assuming the distance from the $\mathrm{X}$-line to the Earth is $80 \%$ of the electron path length). The associated IMF $B_{\mathrm{z}}$ were 1 and $-11 \mathrm{nT}$, respectively for the two events. This is consistent with the expected stretched magnetotail configuration under a strongly southward IMF. The results are also consistent with statistical results of the X-line locations from Geotail measurements.
\end{abstract}

Keywords: magnetotail reconnection, energy-latitude dispersion, polar rain, path length, X-line.

Index terms: 2784, 2776, 2760, 2744, 2723

Key points: An improved method for estimating X-line location. 
Phone/fax: 1-443-778-4593/1-443-778-1641, email: yongliang.zhang@jhuapl.edu

7

8 


\section{Introduction}

Under a southward interplanetary magnetic field (IMF), the dayside anti-parallel reconnection between IMF and the Earth's magnetic field creates open field lines on which solar wind superthermal electrons enter the polar cap and cause polar rain [Fairfield and Scudder, 1985; Wing et al., 1996]. On the dayside, the polar rain electrons appear fairly uniform. However, polar rain electrons often show spatial variations on the nightside, such as large spatial gradients [Gussenhoven et al. 1984; Fairfield et al., 2008], dawn-dusk aligned bars [Zhang et al., 2007], wavy structures [Zhang et al., 2013], a void region or drop-off (gap) near the auroral oval [Meng and Kroehl,1977], and nightside energy-latitude dispersion [Shirai et al., 1997, Zhang et al., 2011]. The void region or gap is due to the magnetotail reconnection that shuts off the supply of solar wind electrons and the loss cone becomes empty after the field-aligned polar rain electrons precipitate into the ionosphere as the newly reconnected magnetic field line continues to convect earthward [Wing and Zhang, 2015]. It takes sometime for the ambient plasma sheet electrons to fill this newly reconnected field line. Figure 1 shows a sketch of polar rain electrons on open field lines (Figure 1a) and newly reconnected (closed) field lines (Figure 1b). 
(a)

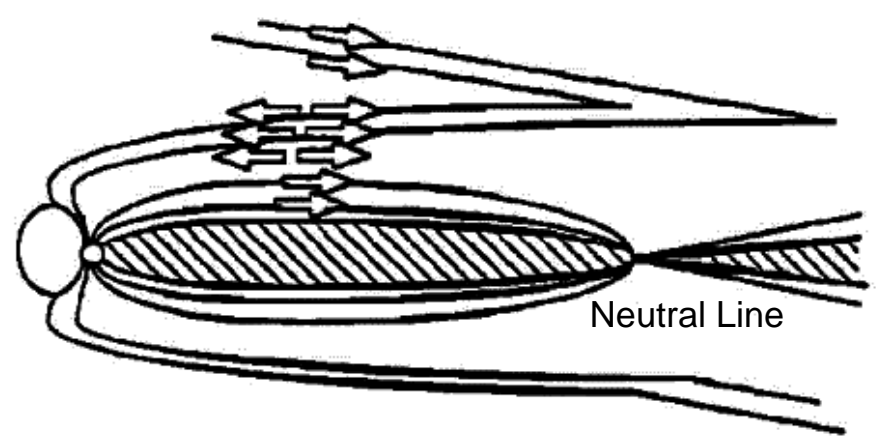

\section{DMSP}

(b)

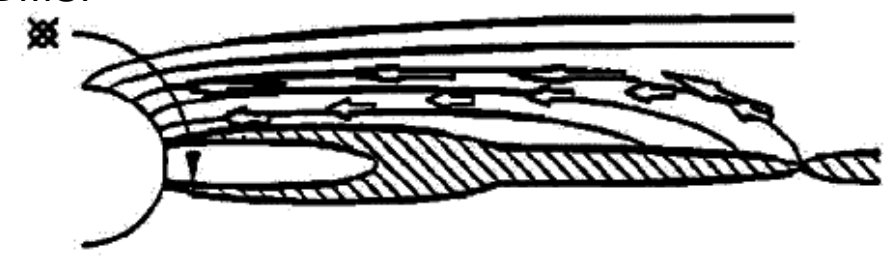

Figure 1. A sketch of polar rain electrons on open field lines (a) and newly reconnect field lines (b). A low earth orbit (LEO) satellite (such as DMSP) may detect the polar rain electron energylatitude dispersion near the nightside auroral oval. This plot is adapted from Figure 1 of Shirai et al. [1997].

Akebono satellite often observed the energy-latitude dispersion in the polar rain electron flux on the nightside. Shirai et al. [1997] attributed the energy dispersion to the disruption of the polar rain by the X-type neutral lines in the magnetotail. At the reconnection location (the neutral line in new Figure 1), the newly reconnected magnetic field carries all polar rain electrons with different energies from the solar wind. After the reconnection, the field line becomes closed and this cuts off any new supply of electrons from the solar wind. Therefore, these polar rain electrons at all energies start to travel to the ionosphere from the reconnection site. Because of the E $\times \mathrm{B}$ drift that is energy independent, both low and high energy electrons will also drift cross field line at the same speed. Though the ExB drift could vary at different locations along the field line, but the net effect of $\mathrm{E} \times \mathrm{B}$ drift can be well characterized by measurements in the ionosphere. Therefore, the polar rain electron energy dispersion can be used to monitor the 
reconnection location in the magnetotail. Such method has been used to estimate the reconnection X-line location based on satellite measurements of polar rain electrons [Shirai et al., 1997; Alexeev et al., 2006, Zhang et al., 2011]. This dispersion method is physically sound and provides reasonable results. However, the method is difficult to be validated due to lack of coincident in situ reconnection measurements in the magnetotail.

Using an open-field line tracing model (APL-OPM) Wing et al. [1996; 2001], Wing and Zhang [2015] successfully reproduced the polar rain energy-latitude dispersion (Figure 2). Since the reconnection or $\mathrm{X}$-line location was precisely set at $\mathrm{X}=-50 \mathrm{R}_{\mathrm{E}}$ and the polar rain electron path lengths can be accurately calculated in the simulation, we can use the simulation data to check the accuracy of the existing method for the X-line location estimation. In general, the path length has a dependence on the energy. This is due to the $\mathrm{E} \times \mathrm{B}$ drift that moves electrons from high to low L-shell field lines. The lower energy electrons would have more time to $\mathbf{E} \times \mathbf{B}$ drift to lower latitudes (low L shell field lines) that have shorter lengths than the high L-shell field lines, resulting in shorter total path lengths. The high energy electrons travel mostly on high L-shell field lines with longer path lengths. For example, the $462 \mathrm{eV}$ electrons (marked by the top or first white triangle in Figure 2) have a path length of $64 \mathrm{R}_{\mathrm{E}}$ while the $32 \mathrm{eV}$ electrons (the bottom or the $6^{\text {th }}$ triangle in Figure 2) have a path length of $56 R_{E}$ [Wing and Zhang, 2015]. The average of the two paths is $60 \mathrm{R}_{\mathrm{E}}$, which is about $20 \%$ longer than the direct straight line distance $\left(50 \mathrm{R}_{\mathrm{E}}\right)$ between the center of the Earth (or the polar ionosphere) and the X-line. Such 20\% difference can be attributed to the curvature of the magnetic field lines and cross-field drift of the electrons. 
Furthermore, Wing and Zhang [2015] found that the path lengths from the traditional or existing method [Shirai et al., 1997; Alexeev et al., 2006; Zhang et al., 2011] were at least 33\% shorter than the lengths by integrating the electron paths in the simulations. Table 1 (adopted from Wing and Zhang [2015]) indicates the five electron path lengths using the traditional method: 43, 39, 36, 32 and $29 \mathrm{R}_{\mathrm{E}}$ (see the $5^{\text {th }}$ row "Length $\left(\mathrm{R}_{\mathrm{E}}\right.$ )" in Table 1). These path lengths were determined using the electron energies and times of the pairs (white triangles in Figure 2): (a) $1^{\text {st }}-2^{\text {th }}$, (b) $1^{\text {nd }}$ $3^{\text {th }}$, (c) $1^{\text {rd }}-4^{\text {th }}$, (d) $1^{\text {th }}-5^{\text {th }}$, (e) $1^{\text {th }}-6^{\text {th }}$ (see equation 4 of Wing and Zhang [2015]). The average of above lengths is about $36 \mathrm{R}_{\mathrm{E}}$ which is $\sim 60 \%$ of true average $\left(60 \mathrm{R}_{\mathrm{E}}\right)$. The reference time in Table 1 is referred to the $1^{\text {st }}$ white triangle in Figure 2. Note the longest length ( $43 R_{\mathrm{E}}$ from the current algorithm using the electrons pairs of 462 and $314 \mathrm{eV})$ is much smaller than the length $\left(64 \mathrm{R}_{\mathrm{E}}\right)$ from the simulation for the $462 \mathrm{eV}$ electron. Similar results are seen for other pairs of electrons. Such significant differences indicate a systematic error in the results from the current method. Section 3 introduces an improved method to reduce the systematic error. Statistical errors are discussed in Section 5.2. 


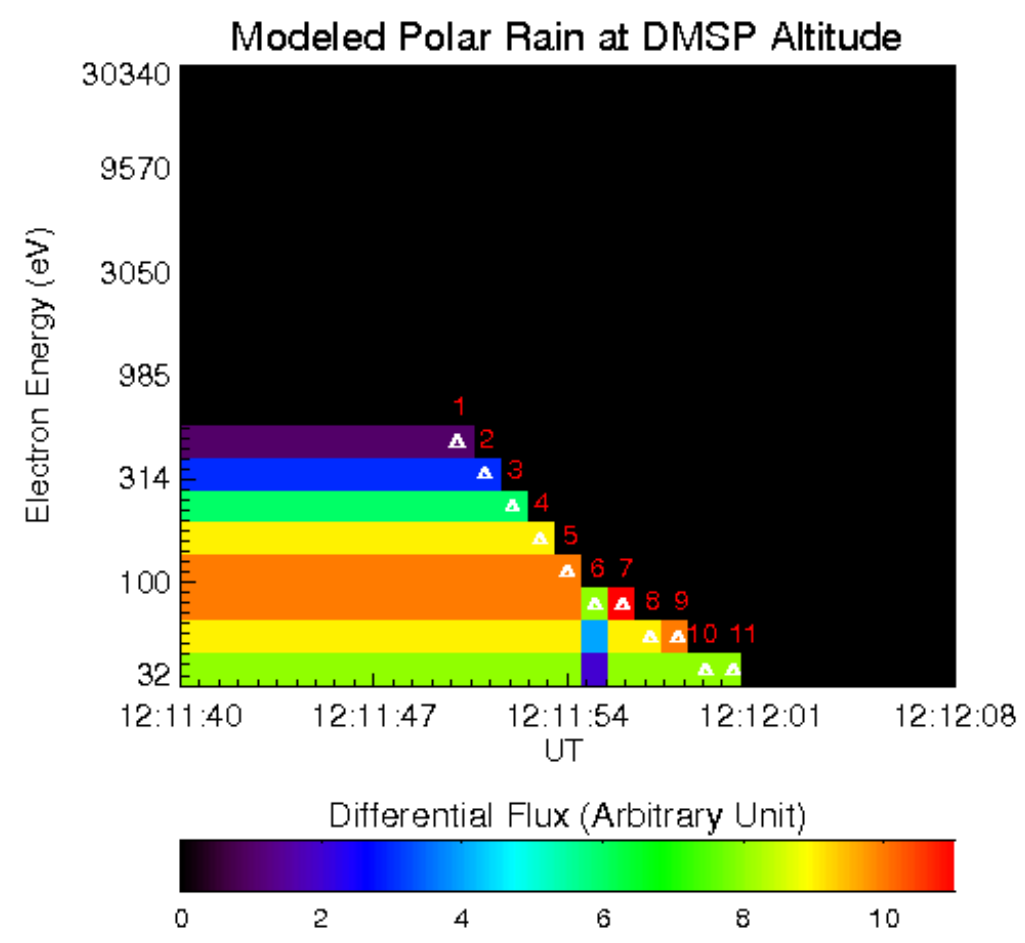

Figure 2. Simulated polar rain electron spectra along a DMSP path. The electron spectra between 12:11:40 and 12:11:49 UT represent the normal polar rain. There is clear electron energy dispersion in the middle of the plot. The white triangles indicate the identified locations of the dispersion. They are used to determine the electron path lengths between DMSP and magnetotail reconnections sites. This plot is reproduced from Wing and Zhang, [2015].

Table 1. Dispersion time, energy and estimated electron path lengths from the model (adapted from Table 1 of Wing and Zhang [2015])

\begin{tabular}{|l|l|l|l|l|l|l|}
\hline Position & 1 st & 2nd & 3 rd & 4 th & 5 th & $6^{\text {th }}$ \\
\hline UT & $12: 11: 50$ & $12: 11: 51$ & $12: 11: 52$ & $12: 11: 53$ & $12: 11: 54$ & $12: 11: 55$ \\
\hline $\begin{array}{l}\text { Ref Time } \\
(\mathrm{sec})\end{array}$ & 0 & 1 & 2 & 3 & 4 & 5 \\
\hline
\end{tabular}




\begin{tabular}{|l|l|l|l|l|l|l|}
\hline $\begin{array}{l}\text { Energy } \\
(\mathrm{ev})\end{array}$ & 462 & 314 & 215 & 147 & 100 & 69 \\
\hline $\begin{array}{l}\text { Path Length } \\
\text { (S) in } \mathrm{R}_{\mathrm{E}}\end{array}$ & 43 & 39 & 36 & 32 & 29 & \\
\hline $\begin{array}{l}\text { Improved } \\
\text { Path Length } \\
\text { (S) in } \mathrm{R}_{\mathrm{E}}\end{array}$ & 61 & 60 & 59 & 60 & 61 & \\
\hline
\end{tabular}

\section{Summary of the existing method}

In order to understand the assumptions and errors behind the current (traditional or existing) method, the method is briefly summarized here. An electron with a constant velocity $\mathrm{V}_{1}$ would take time $\left(t_{1}-t_{0}\right)$ to travel a distance $S_{1}$ (see equation (1)), where $t_{0}$ is the time of the reconnection (the last solar wind electron injection), $t_{1}$ is the time for the electron to be observed in the ionosphere (e.g. DMSP satellite), and $\mathrm{S}_{1}$ is electron path length from X-line to the ionosphere. Equation (2) applies to an electron with a different velocity $\left(\mathrm{V}_{2}\right) . \mathrm{S}_{1}$ is not usually the same as $\mathrm{S}_{2}$.

$$
\begin{aligned}
& t_{1}-t_{0}=\frac{S_{1}}{V_{1}} . \\
& t_{2}-t_{0}=\frac{S_{2}}{V_{2}} .
\end{aligned}
$$

While $t_{1}, t_{2}, V_{1}$, and $V_{2}$ can be measured by low altitude satellites, $t_{0}, S_{1}$ and $S_{2}$ are unknown. The terms $\left(t_{1}-t_{0}\right)$ or and $\left(t_{2}-t_{0}\right)$ are the electron traveling time from the reconnection site (neutral line, see Figure 1) to the polar ionosphere (e.g. DMSP altitude around $840 \mathrm{~km}$ ) at parallel speeds of 
$\mathrm{V}_{1}$ and $\mathrm{V}_{2}$, respectively. Equations (1) and (2) are not sufficient to solve the three unknown parameters. Hence, an assumption is needed. Assuming $\mathrm{S}_{1} \approx \mathrm{S}_{2}=\mathrm{S}$, we obtain equation (3),

$$
\Delta t=t_{1}-t_{2}=S *\left(\frac{1}{V_{1}}-\frac{1}{V_{2}}\right) .
$$

where $\Delta t$ is the time difference between two polar rain electrons with velocities of $V_{1}$ and $V_{2}$ when they arrive at the ionosphere altitude.

Due to non-zero $\mathrm{E} \times \mathrm{B}$ drift that is independent of electron energy, within $\Delta \mathrm{t}$ the electrons also move a distance $\mathrm{L}$ in the direction of $\mathrm{E} \times \mathrm{B}$ drift at the ionosphere altitude. So, $\Delta \mathrm{t}=\mathrm{L} / \mathrm{V}_{\mathrm{p}}$, where $\mathrm{V}_{\mathrm{p}}$ is the $\mathrm{E} \times \mathrm{B}$ drift speed. However, electron observations are usually made from satellites moving at speed $\mathrm{V}_{\mathrm{s}}$. Hence, $\Delta \mathrm{t}$ in the satellite reference frame $\left(\Delta \mathrm{t}^{*}\right)$ can be expressed as $\Delta \mathrm{t}^{*}=\mathrm{L} / \mathrm{V}_{\mathrm{s}}$. Therefore, we obtain $\Delta \mathrm{t}=\left(\mathrm{V}_{\mathrm{s}} / \mathrm{V}_{\mathrm{p}}\right) \Delta \mathrm{t}^{*}$ for the case $\mathrm{V}_{\mathrm{s}}$ is parallel to $\mathrm{V}_{\mathrm{p}}$. If $\mathrm{V}_{\mathrm{s}}$ and $\mathrm{V}_{\mathrm{p}}$ are not parallel, then a component of $\mathrm{V}_{\mathrm{p}}$ that is parallel to $\mathrm{V}_{\mathrm{s}}$ would be used instead. By replacing $\Delta \mathrm{t}$ in equation (3), we obtain the expression for the electron path length (S)

$$
S=\left(\frac{V_{s} \Delta t^{*}}{V_{p}}\right) /\left(\frac{1}{V_{1}}-\frac{1}{V_{2}}\right)
$$

This equation is similar to the one used by Alexeev et al. [2006]. Equations (3) and (4) are derived with the assumption $\mathrm{S}_{1}=\mathrm{S}_{2}=\mathrm{S}$, which introduces system biases. On the other hand, the statistical error in $V_{p}$ and $\Delta t^{*}$ are the major sources to the uncertainty in $S$ because $V_{s}, V_{1}$, and $V_{2}$ can usually be accurately determined (see Section 5.2 for more detailed discussion on statistical errors).

The time (UT) and electron energies associated with the first 6 triangles in Figure 2 are listed in Table 1. The energy dispersion associated with the last 5 triangles is rather weak and so they are not listed in Table 1. For the convenience of calculating $\Delta t^{*}$ in Equation (4), the time referenced from the first triangle (12:11:50) is also provided in Table 1. 
The model used $\mathrm{V}_{\mathrm{s}}=7.8 \mathrm{~km} / \mathrm{s}$, which is the DMSP satellite speed and $\mathrm{V}_{\mathrm{p}}=\mathbf{E} \times \mathbf{B}$ drift $=$ $1.7 \mathrm{~km} / \mathrm{s}$ where $\mathrm{E}\left(8.5 \times 10^{-2} \mathrm{~V} / \mathrm{m}\right)$ was obtained from the SuperDARN convection pattern and B $\left(\mathbf{5 . 0} \times 10^{-5} \mathbf{T}\right)$ was obtained from the International Geomagnetic Reference Field (IGRF) at the DMSP satellite location. Using equation (4), we calculated S (Path Length) for five pairs of selected points in Table 1: $1^{\text {st }}-2^{\text {nd }}, 1^{\text {st }}-3^{\text {rd }}, 1^{\text {st }}-4^{\text {th }}, 1^{\text {st }}-5^{\text {th }}$, and $1^{\text {st }}-6^{\text {th }}$. The path lengths are listed in Table 1 (the row with "Path Length"). The selection of $1^{\text {st }}$ data point (462 eV electrons) in each pair aims to reduce error in the estimated $\mathrm{S}$ because dispersion is more significant between two electrons with a large difference in their energies.

The APL-OPM simulations reveals two important facts: (1) the electron path lengths are inconsistent when using electrons with different energies, (2) the traditional method leads to a path length that is about only about $60 \%$ of true path length on average. All of these two discrepancies are due to $\mathbf{E} \times \mathbf{B}$ drift (thus energy dependent path length) and an assumption of same path length of electrons with different energies. Understanding these error sources for equation (4) provides a way to improve the traditional method.

\section{An improved method for estimating the electron path length}

\subsection{Improved method description}

In an attempt to improve the electron path length estimation in equation (4) and reduce the system bias, we introduce a new parameter: an energy adjustment $(\Delta \mathrm{E})$ to the polar rain electron energy. This parameter simply changes $V_{1}$ and $V_{2}$ in equation (4) and is applied to all electrons with different energies for a given event. This parameter is derived by fitting the data points as described next. The $\Delta \mathrm{E}$ (either positive or negative) is added to the DMSP electron energy 
values. Table 1 lists the 5 distances for the case with $\Delta \mathrm{E}=0 \mathrm{eV}$ (the original equation 4 , see the row "Path Length (S) in $\mathrm{R}_{\mathrm{E}}$ "). These distances are plotted in Figure 3b. The mean distance (36 \pm $5 R_{E}$ ) is indicated in Figure $3 b$ (herein the error indicates standard deviation). Figure 3a shows the case for $\Delta \mathrm{E}=-20 \mathrm{eV}$ with an average distance of $31 \pm 6 \mathrm{R}_{\mathrm{E}}$. These distances are not consistent with each other and it is not clear which one would be better. More importantly, these distances are much shorter than those obtained from the model. Figure $3 \mathrm{c}$ shows the case with $\Delta \mathrm{E}=99 \mathrm{eV}$. The distances are relatively constant or consistent $\left(61,60,59,60\right.$ and $61 \mathrm{R}_{\mathrm{E}}$, see the last row in Table 1) with an average of $60 \mathrm{R}_{\mathrm{E}}$. Their standard deviation is $0.7 \mathrm{R}_{\mathrm{E}}$ (round to $1 \mathrm{R}_{\mathrm{E}}$ ) which is much smaller than those in Figures $3 a, 3 b$, and $3 d(\Delta E=250 \mathrm{eV})$. In addition to the cases shown in Figure 3, we also ran many cases with $\Delta \mathrm{E}$ changing from -30 to $270 \mathrm{eV}$. Figure 4 shows the dependence of the distance error or standard deviation on $\Delta \mathrm{E}$. The minimum error occurs at $\Delta \mathrm{E}=99 \mathrm{eV}$. This is the case shown in Figure $3 \mathrm{c}$ where the distances are essentially independent of the electron energies. Furthermore, the mean distance $\left(60 \mathrm{R}_{\mathrm{E}}\right)$ is identical to the average distance $\left(60 \mathrm{R}_{\mathrm{E}}\right)$ from the simulation. This indicates that $\Delta \mathrm{E}$ is a useful parameter for improving the estimation of the electron path lengths from the reconnection site to the polar ionosphere. 

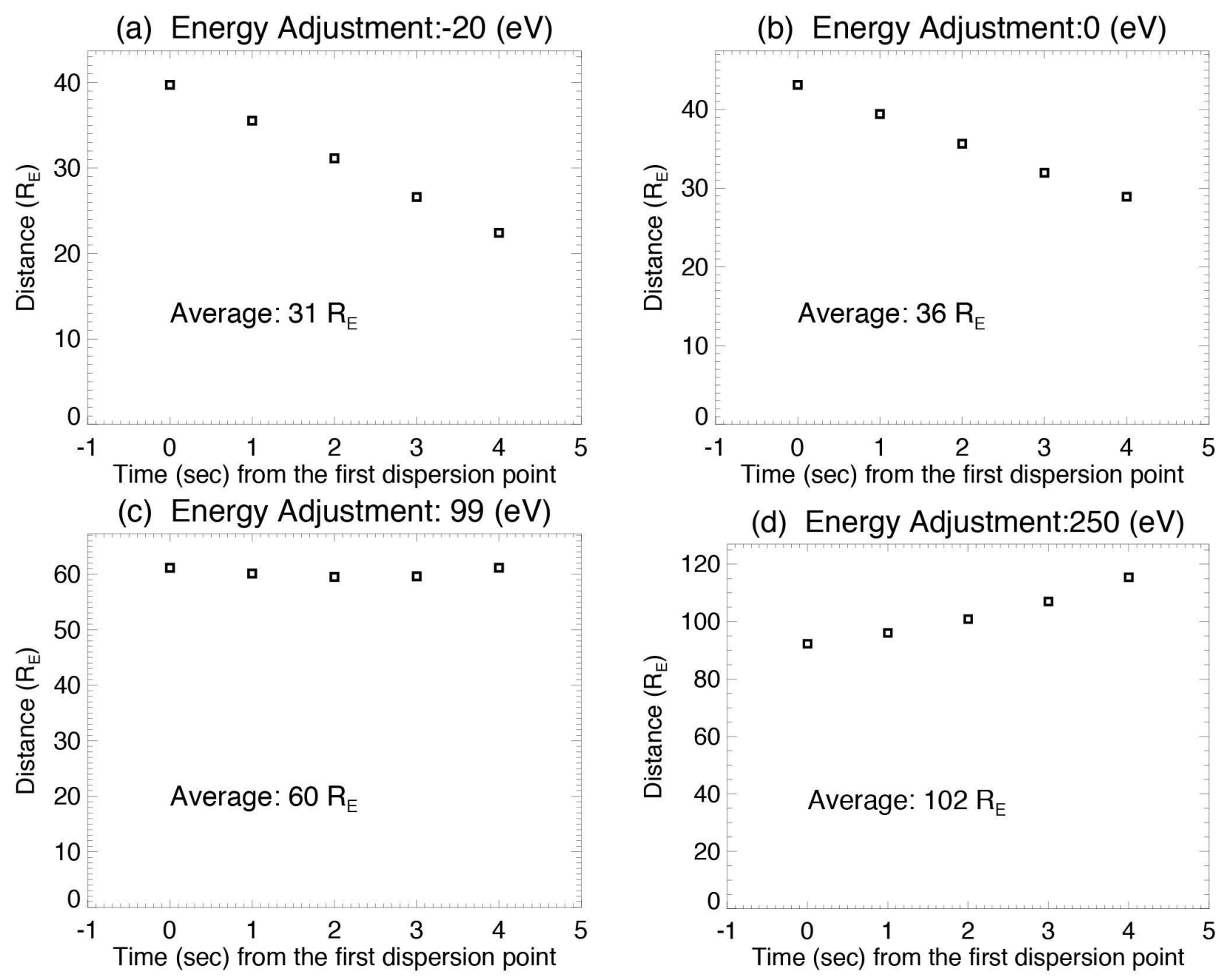

Figure 3. Estimated electron path lengths between DMSP and magnetotail reconnection locations for the simulated polar rain electron dispersion (first 6 triangles shown in Figure 1). The four panels are for different energy adjustments (a) $-20 \mathrm{eV}$, (b) $0 \mathrm{eV}$, (c) $99 \mathrm{eV}$, and (d) $250 \mathrm{eV}$. The average distance for each case is listed in the plots. The associated errors are around 6, 5, 1, 8, $\mathrm{R}_{\mathrm{E}}$, respectively. 


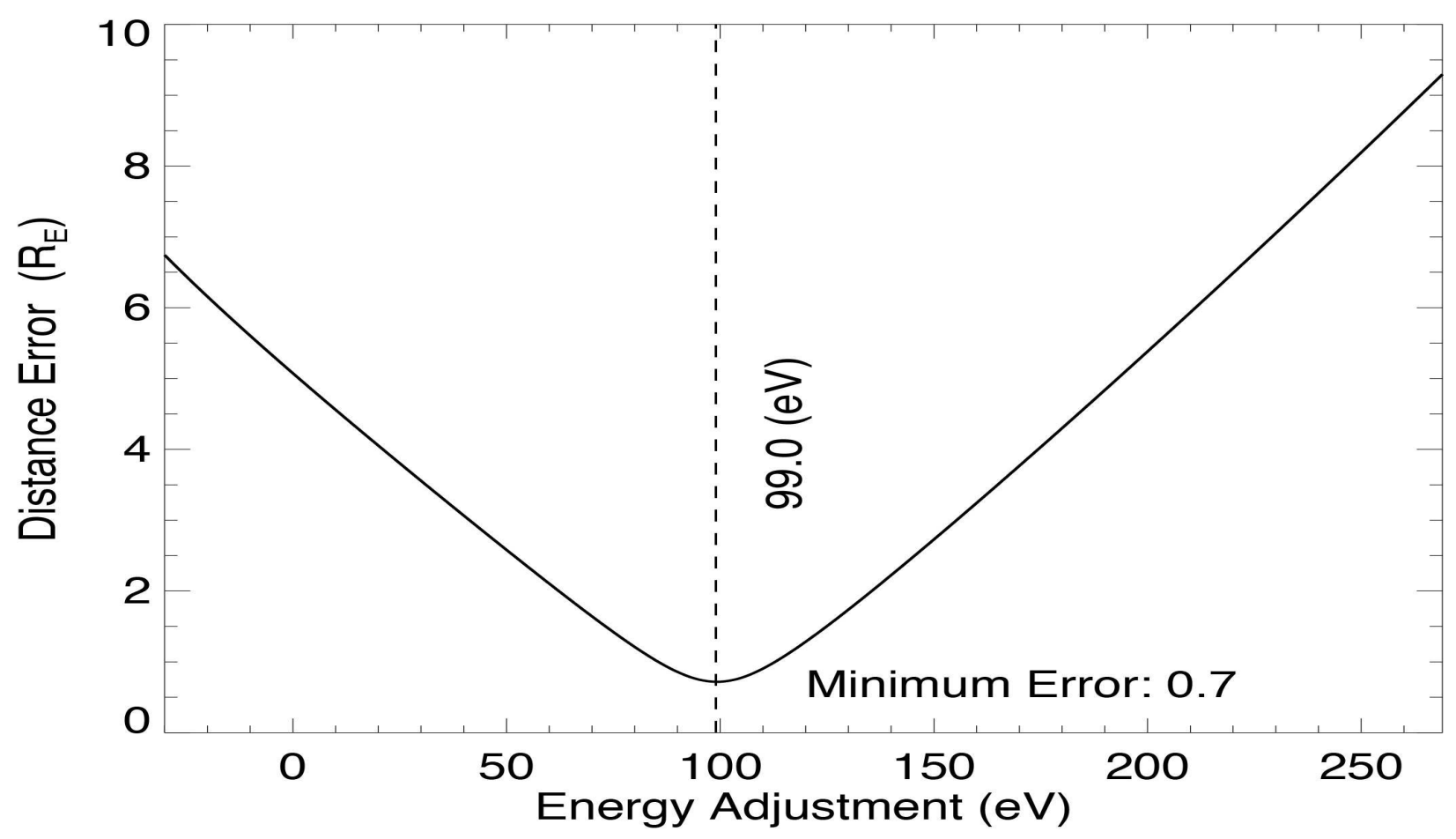

Figure 4. Dependence of the distance errors (see Figure 3 ) on the energy adjustment $(\Delta \mathrm{E})$. The minimum error occurred at $\Delta \mathrm{E}=99 \mathrm{eV}$.

It is important to note that the term $\Delta \mathrm{E}$ is is only a mathematical parameter to minimize the error due to the assumption of the same path lengths of polar rain electrons with different energies. The simulation [Wing and Zhang 2015] indicates that path length of high energy electrons is longer than that of low energy electrons. Adding $\Delta \mathrm{E}$ increases electron velocity $(\mathrm{V})$ and the path length but the time difference $\left(\Delta \mathrm{t}^{*}\right)$ remains unchanged in measurements or simulations. However, the impact of $\Delta \mathrm{E}$ on the path length is more significant to the low energy electrons than the high energy ones. This effectively increases the path length associated with low energy electrons and directly reduces the systematic error introduced by the assumption of equal path length. Applying the improved method to the simulated data leads a consistent path length. This confirms the usefulness of the method. 
In the simulation [Wing and Zhang, 2015], there is no energization or field-aligned acceleration. If there is such energization, the measured electron energy in the energy diffusion region by satellites at the ionosphere will be higher than those in the polar rain without energy dispersion. However, the two real events observed by the DMSP measurements (next section) do not show such a feature. This indicates that the energization is unlikely to occur.

\section{Real Events}

The above improved algorithm has been applied to two real DMSP dispersion events: one for weakly northward and one strongly southward IMF. Wing and Zhang [2015] estimated the X-line location in these two events using the existing or old method. Here, we use the new method on these same events to illustrate the differences between the old and new methods. Figure 4a shows the electron differential energy flux from DMSP F15 satellite around 19:48 UT on April 17, 2002. The associated Interplanetary Mangnetic Field (IMF) $\mathrm{B}_{\mathrm{x}}, \mathrm{B}_{\mathrm{y}}$ and $\mathrm{B}_{\mathrm{z}}$ from ACE satellite were $-6,13$, and $1 \mathrm{nT}$, respectively, indicating a weakly northward $\mathrm{IMF} \mathrm{B}_{\mathrm{z}}$ and a dominant IMF $B_{y}$. Weak polar rain electrons were seen between 19:48:15 and 19:48:28 UT (left side of Figure 5a). The 5 white triangles are again used to mark the positions of the electron dispersion. The corresponding UT and electron energies are 19:48:23, 19:48:24, 19:48:25, 19:48:26, 19:48:27 and 3040, 1393, 640, 299, $200 \mathrm{eV}$, respectively. Using the equation (4) with $\Delta \mathrm{E}=0 \mathrm{eV}, \mathrm{V}_{\mathrm{s}}=7.8 \mathrm{~km} / \mathrm{s}$ (DMSP satellite speed) and ionospheric plasma drift speed along DMSP path $\left(\mathrm{V}_{\mathrm{p}}=1.7 \mathrm{~km} / \mathrm{s}\right.$ from SuperDarn convection map [Ruohoniemi and Greenwald, 1996] $\begin{array}{llll}\text { and } & \text { DMSP } & \text { drift } & \text { speed }\end{array}$ (http://cindispace.utdallas.edu/DMSP/dmsp_data_at_utdallas.html), we obtained the mean path lengths of $40 \pm 7 R_{E}\left(49,39,32 R_{E}\right.$ using the traditional or old method) and $67 \pm 1 R_{E}(68,65,68$ $\mathrm{R}_{\mathrm{E}}$ using the improved or new method) based on the first 4 dispersion data points. The new mean 
path length $\left(67 \mathrm{R}_{\mathrm{E}}\right.$ with $\left.\Delta \mathrm{E}=498 \mathrm{eV}\right)$ is about $68 \%$ longer than the old one $\left(40 \mathrm{R}_{\mathrm{E}}\right)$. Again, the distances from the new method are roughly independent of the electrons energies. Assuming the same ratio $(80 \%)$ between the reconnection $\mathrm{X}$ location $\left(50 \mathrm{R}_{\mathrm{E}}\right)$ and the mean electron path length $\left(60 \mathrm{R}_{\mathrm{E}}\right)$ in the APL-OPM model run, the reconnection location for the event is estimated at $\mathrm{X}=$ $80 \% *\left(-67 \mathrm{R}_{\mathrm{E}}\right)=-54 \mathrm{R}_{\mathrm{E}}$. If we use the old path length $\left(40 \mathrm{R}_{\mathrm{E}}\right)$, the reconnection location is at $\mathrm{X}$ $=80 \% *\left(-40 R_{E}\right)=-32 R_{E}$, which is much closer to the Earth than the typical locations at $X=-50$ to $-150 R_{E}$ from Geotail observations [Shirai et al, 1997]. On the other hand, the $X=-54 R_{E}$ is consistent with the Geotail results. This confirms that the new method improves the reconnection location estimation. The old or existing method under-estimates the X location by about $40 \%$ (32 $R_{E}$ versus $\left.54 R_{E}\right)$.

Figure 5b shows another example of polar rain electron dispersion from DMSP F15 around 01:24 UT on August 2, 2002. The 5 white triangles in Figure 5b mark the electron dispersion locations at UT 01:25:14, 01:25:15, 01:25:16, 01:25:17, 01:25:18 and electron energies of 1393, 640, 437, 437, $299 \mathrm{eV}$. The associated IMF $\mathrm{B}_{\mathrm{x}}, \mathrm{B}_{\mathrm{y}}$ and $\mathrm{B}_{\mathrm{z}}$ are $1.5,-10$, and -11 nT, respectively, indicating a highly southward IMF. The associated DMSP and plasma speeds are 7.8 and $1.7 \mathrm{~km} / \mathrm{s}$, respectively. To minimize the distance errors using the new method and the first 4 dispersion points, $\Delta \mathrm{E}$ is set to $380 \mathrm{eV}$. This leads to self-consistent distances $(114,113$, $\left.114 \mathrm{R}_{\mathrm{E}}\right)$ with an average of $114 \pm 1 \mathrm{R}_{\mathrm{E}}$. The old method $(\Delta \mathrm{E}=0 \mathrm{eV})$ gives distances of 74,67 , and $61 R_{E}$ with a mean of $67 \pm 5 R_{E}$. The new path length $\left(114 R_{E}\right)$ is about $69 \%$ longer than the old path length $\left(67 \mathrm{R}_{\mathrm{E}}\right)$. This indicates that the old method again under-estimates the distance by $\sim 40 \%$ (67 versus $114 \mathrm{R}_{\mathrm{E}}$ ). Using the same $80 \%$ ratio, the estimated reconnection location is at $X=-80 \% * 114=-91 R_{E}$. Such a distance is nearly double of the distance on the April 17, 2002. 
(a) DMSP F15, South, 19:48, 04/17, 2002

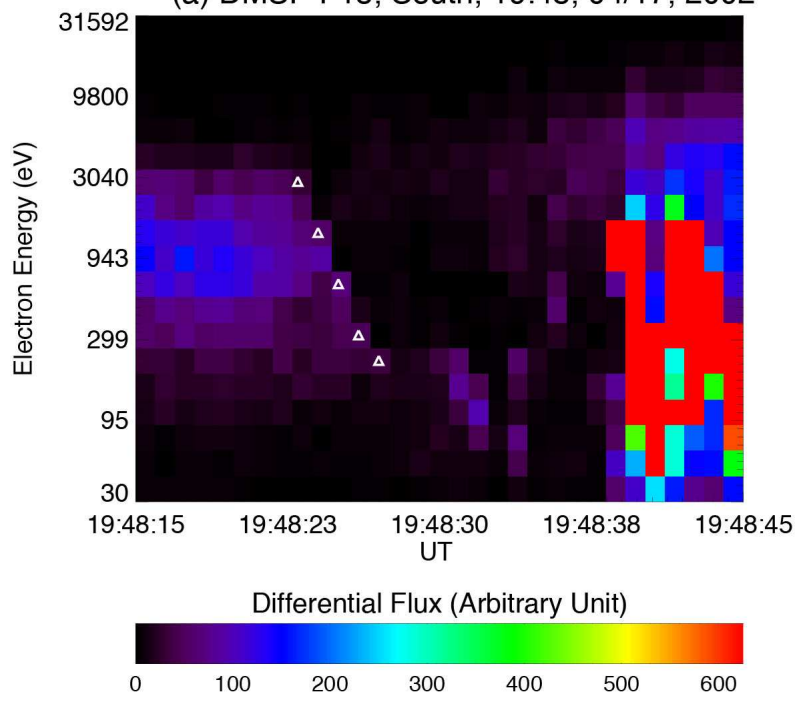

(b) DMSP F15, South, 01:24, 08/02, 2002

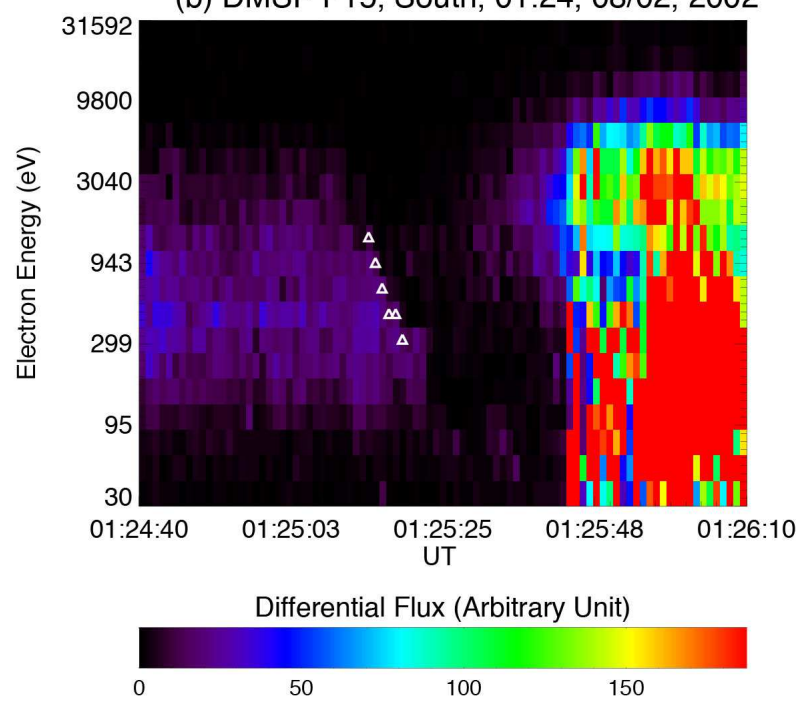

Figure 5. Electron spectra from DMSP F15 around (a) April 17, 2002 19:48 UT and (b) August 2, 2002 01:24 UT. The white triangles mark the location of polar rain energy dispersion (Adapted from Figure 3 of Wing and Zhang [2015]).

\section{Discussion}

\subsection{IMF $B_{z}$ dependence of the reconnection location}

Based on a statistical study using Geotail observations during geomagnetically active time (Kp $\geq 3$ ), Nishda et al. [1995] found that at least $75 \%$ of the reconnection of open field lines occurs inside $150 \mathrm{R}_{\mathrm{E}}$ and at least $39 \%$ occurs inside $95 \mathrm{R}_{\mathrm{E}}$. Our estimations of the deep tail reconnection locations $\left(\mathrm{X}=\sim-54\right.$ and $\sim-91 \mathrm{R}_{\mathrm{E}}$ ) of the two DMSP events are within the ranges determined by the Geotail measurements. Global magneto-hydrodynamic (MHD) simulations also indicate that the magnetotail became more stretched when $\mathrm{IMF} \mathrm{B}_{\mathrm{z}}$ was more southward from -2.5 to $-20 \mathrm{nT}$ [Cai et al., 2008]. This suggests that the magnetotail reconnection is expected to occur at locations further away from the Earth when IMF $\mathrm{B}_{\mathrm{z}}$ is more southward [c.f., Wing et al., 2006]. Our estimations of the two reconnection locations $\left(X=\sim-54\right.$ and $\left.\sim-91 R_{E}\right)$ under IMF $B_{z}=1$ and -11 
nT support such simulation results and are consistent with the Geotail estimation of the $\mathrm{X}$ line location (X=-50 to $-150 \mathrm{R}_{\mathrm{E}}$ [Shirai, et al., 1997]).

\subsection{Statistical Error estimation}

Unlike the case in the simulation where all parameters are precisely defined, the measurements in the two real events subject to statistical or random errors. Assuming the statistical errors in the parameters of equation (4) are independent, the relative variance $(\delta S)^{2} / S^{2}$ of the electron path length $\mathrm{S}$ can be presented as:

$$
\frac{(\delta S)^{2}}{S^{2}}=\frac{\left(\delta V_{s}\right)^{2}}{V_{s}^{2}}+\frac{\left(\delta V_{p}\right)^{2}}{V_{p}^{2}}+\frac{\left(\delta \Delta t^{*}\right)^{2}}{\left(\Delta t^{*}\right)^{2}}+\left(\frac{V_{2}}{V_{2}-V_{1}}\right)^{2} \frac{\left(\delta V_{1}\right)^{2}}{V_{1}^{2}}+\left(\frac{V_{1}}{V_{2}-V_{1}}\right)^{2} \frac{\left(\delta V_{2}\right)^{2}}{V_{2}^{2}}
$$

It is reasonable to assume $V_{1}>>V_{2}$ as the DMSP electron energies have a logarithm dependence on their channels. The equation (5) is simplified as:

$$
\frac{(\delta S)^{2}}{S^{2}}=\frac{\left(\delta V_{s}\right)^{2}}{V_{s}^{2}}+\frac{\left(\delta V_{p}\right)^{2}}{V_{p}^{2}}+\frac{\left(\delta \Delta t^{*}\right)^{2}}{\left(\Delta t^{*}\right)^{2}}+\frac{\left(\delta V_{2}\right)^{2}}{V_{2}^{2}} \ldots \ldots \ldots(6)
$$

The DMSP satellites are in a circular orbit with a fixed period (T) around $101 \mathrm{~min}$. Even if we assume a $1 \mathrm{~min}$ (upper limit) in the period variation $(\delta \mathrm{T})$, we have $\delta \mathrm{V}_{\mathrm{s}} / \mathrm{V}_{\mathrm{s}}=\delta \mathrm{T} / \mathrm{T}<1 \%$ which is negligible. The sampling time for each DMSP particle data is $1 \mathrm{~s}$. The average sampling time accuracy or error is expected to be half of the sampling time $\left(\delta \Delta t^{*}=0.5 \mathrm{~s}\right)$. Therefore, relative error due to time sampling $\left(\delta \Delta \mathrm{t}^{*} / \Delta \mathrm{t}^{*}\right)$ is from $\sim 10 \%$ (if using two data points with $\Delta \mathrm{t}^{*}=5 \mathrm{~s}$ ) up to $50 \%$ (using data points with a minimum $\Delta \mathrm{t}^{*}=1 \mathrm{~s}$ ). Typically, the DMSP dispersion data include 4-6 data points $\left(\Delta \mathrm{t}^{*}=3\right.$ to $5 \mathrm{~s}$ ). Therefore, the error due to sampling time ranges from $10 \%$ to $20 \%$. The absolute errors in the SuperDarn plasma drift speed $\left(\mathrm{V}_{\mathrm{p}}\right)$ are around $\sim 100$ to $\sim 150 \mathrm{~m} / \mathrm{s}$ [Robin Barns, private communication, 2014]. The nightside polar rain dispersion events are usually associated with high plasma drift speed $(\sim 1000-2000 \mathrm{~m} / \mathrm{s})$ under a southward IMF. This 
indicates that the SuperDarn drift speed has a relative error of $\sim 10-15 \%\left(\delta \mathrm{V}_{\mathrm{p}} / \mathrm{V}_{\mathrm{p}}\right)$. Finally, the energies in the DMSP particle channels are fixed and do not change with time. Their relative error $\left(\delta \mathrm{V}_{2} / \mathrm{V}_{2}\right)$ could be ignored too, when compared to $\left(\delta \mathrm{V}_{\mathrm{p}} / \mathrm{V}_{\mathrm{p}}\right)$. Considering all of the above facts, the equation (6) is further reduced to $(\delta \mathrm{S})^{2} / \mathrm{S}^{2} \approx\left(\delta \mathrm{V}_{\mathrm{p}}\right)^{2} /\left(\mathrm{V}_{\mathrm{p}}\right)^{2}+\left(\delta \Delta \mathrm{t}^{*}\right)^{2} /\left(\Delta \mathrm{t}^{*}\right)^{2}$. Using the values of $10-15 \%$ for $\delta \mathrm{V}_{\mathrm{p}} / \mathrm{V}_{\mathrm{p}}$ and $10-20 \%$ for $\delta \Delta \mathrm{t}^{*} / \Delta \mathrm{t}^{*}$, the relative random error $(\delta \mathrm{S} / \mathrm{S})$ in the path length ranges from $\sim 15 \%$ to $25 \%$. This simple error analysis indicates that the SuperDarn plasma drift speed and the sampling time are the dominant error sources and the relative error in the estimated electron path length or reconnection location is around $15-25 \%$. This suggests that the statistical errors in the reconnection location estimations are around a few $R_{E}$ to $\sim 15 R_{E}$ depending on the reconnection location. The above error analysis applies specifically to the DMSP particle and SuperDarn plasma convection data. If particle data with higher time resolution and more accurate plasma drift data are used, the relative error in the path length will be smaller.

\section{Summary and conclusion}

The successful APL-OPM simulations [Wing and Zhang, 2014] indicate that the polar rain electron path lengths between the $\mathrm{X}$-line and the polar ionosphere from the existing method are at least 33\% systematically shorter than the true path length. We propose an improvement to the existing method by introducing a fitting parameter, energy adjustment, to the polar rain electron energies. This energy adjustment is obtained by minimizing errors among the path lengths using electrons with different energies. This improved method produces path lengths that are roughly energy-independent (59-61 $R_{E}$ ) with an average path length of $60 R_{E}$, which agrees very well with the actual average length from the APL-OPM runs. We applied the new method 
to two dispersion events from DMSP observations: one for weakly northward IMF (April 17 , 2002) and one for strongly southward IMF (August 2, 2002). We obtained electron path lengths of 67 and $114 R_{E}$, respectively, which correspond to reconnection locations at $X=\sim-54$ and -91 $\mathrm{R}_{\mathrm{E}}$, respectively, assuming the same ratio $(80 \%)$ between the reconnection location $\left(50 \mathrm{R}_{\mathrm{E}}\right)$ and the path length $\left(60 \mathrm{R}_{\mathrm{E}}\right)$ obtained in the model. The results are consistent with the more stretched field line configuration under a southward IMF than a northward IMF. Using plasma convection data from SuperDarn and particle data from DMSP will lead to $15-25 \%$ statistical errors in estimated electron path length. The statistical errors could be reduced using more accurate plasma speed and higher sampling rate $(>1 \mathrm{~Hz})$ particle data.

Acknowledgments. AFRL has been helpful in acquisition of DMSP SSJ4/SSJ5. Yongliang Zhang acknowledges the support from NASA grant NNX10AL01G. Simon Wing gratefully acknowledges support from NSF Grants ATM-0802715, and AGS-1058456 and NASA Grant NNX13AE12G. 


\section{References}

Alexeev, I.V., et al. (2006), Remote sensing of a magnetotail reconnection X-line using polar rain electrons, Geophys. Res. Lett., 33, L19105, 10.1029/2006GL027243.

Cai, X., R.C. Clauer, A.J. Ridley, and G. Toth, Investigating the Earth's magnetosphere response to IMF $B_{z}$ magnitude using SWMF, American Geophysical Union, Fall Meeting 2008, abstract \#SM23B-1693.

Fairfield, D. H., and J. D. Scudder (1985), Polar rain: Solar coronal electrons in the Earth's magnetosphere, J. Geophys. Res., 90, 4055.

Fairfield, D. H., S. Wing, P. T. Newell, J. M. Ruohoniemi, J. T. Gosling, and R. M. Skoug (2008), Polar rain gradients and field-aligned polar cap potentials, J. Geophys. Res., 113, A10203, doi:10.1029/2008JA013437.

Gussenhoven, M.S., et al. (1984), Morphology of the polar rain, J. Geophys. Res., 89, 9785, 1984.

Meng, C.-I., and H.W. Kroehl (1977), Intense uniform precipitation of low-energy electrons over the polar cap, J. Geophys. Res., 82, 2305.

Nishida, A., T. Mukai, T. Yamamoto, Y. Saito, and S. Kokubun, GEOTAIL observations on the reconenction process in the distant tail in geomagnetically active times, Geophys. Res. sLett., 22, 2453-2456, 1995.

Ruohoniemi, J. M., and R. A. Greenwald, Statistical patterns of high-latitude convection obtained from Goose Bay HF radar observations, J. Geophys. Res., 101, 21,743, 1996.

Shirai, H., et al. (1997), Drop-off of the polar rain flux near the plasma sheet boundary, $J$. Geophys. Res., 102, 2271-78. 
Wing, S., P.T. newell, and T.G. Onsager, Modeling the entry of magnetosheath electorns into the dayside ionosphere, J. Geophys. Res., 101, 13155, 1996.

Wing, S., P.T. Newell, and J.M. Rouhoneimi, Double cusp: Model prediction and observational verification, J. Geophys. Res., 106, 25571, 2001.

Wing, S., J. R. Johnson, and M. Fujimoto (2006), Timescale for the formation of the cold-dense plasma sheet: A case study, Geophys. Res. Lett., 33, L23106, doi:10.1029/2006GL027110.

Wing, S., and Y. Zhang, The open-closed boundary and polar rain energy dispersion in the nightside ionosphere, AnGeo Comm., 33, 39-46, 2015.

Zhang Y., L.J. Paxton and A.T.Y. Lui (2007), Polar rain aurora, Geophys. Res. Lett., 34, L20114, doi:10.1029/2007GL031602.

Zhang, Y., L. J. Paxton, and H. Kil (2011), Nightside polar rain aurora boundary gap and its applications for magnetotail reconnection, J. Geophys. Res., 116, A11214, doi:10.1029/2011JA016884.

Zhang, Y., L. Paxton, and H. Kil (2013), Large-scale structures in the Polar Rain, Geophys. Res. Lett., 40, 5576-5580, doi:10.1002/2013GL058245. 